\title{
Inheritance of Flower Color in Anagallis monelli L.
}

\author{
Rosanna Freyre ${ }^{1}$ \\ Plant Biology, University of New Hampshire, G36 Spaulding Hall, Durham, \\ NH 03824
}

\section{Robert J. Griesbach}

Floral and Nursery Plant Research, U.S. National Arboretum, U.S. Dept. of Agriculture, Agricultural Research Service, BARC-West, Building 010A, Beltsville, MD 20705

Additional index words. Primulaceae, anthocyanins, flavonoids

Abstract. Plants of Anagallis monelli in their native habitat or in cultivation have either blue or orange flowers. Clonally propagated cultivars, seed obtained from commercial sources and the resulting plants were grown in a greenhouse at the University of New Hampshire. $F_{2}$ progeny obtained from hybridization between blue- and orange-flowered plants had blue, orange or red flowers. There were no significant differences in petal pH of orange-, blue-, and red-flowered plants that could explain the differences in flower color. Anthocyanidins were characterized by high-performance liquid chromatography. Results indicated that blue color was due to malvidin, orange to pelargonidin, and red to delphinidin. Based on our segregation data, we propose a three-gene model to explain flower color inheritance in this species.

The genus Anagallis is in the family Primulaceae, although recent phylogenetic studies based on DNA sequence data from three chloroplast genes and morphology have placed it in the family Myrsinaceae (Källersjö et al., 2000). There are about 28 species in the genus Anagallis, mostly native to Europe, Asia, Africa and America (Clapham et al., 1987). Anagallis monelli L. (taxonomic synonyms $A$. collina Schousboe, A. linifolia L.) is a shortlived perennial with blue flowers found in dry, open habitats in southwestern Europe (Tutin et al., 1972). Wild forms are diploid $(2 n=20)$ (Talavera et al., 1997) and self-incompatible (Gibbs and Talavera, 2001; Talavera et al., 2001). A variant, diploid form of A. monelli with orange flowers is found in southern Italy and northern Africa (Freyre, unpublished data; Talavera, personal communication).

Cultivated forms of A. monelli (blue pimpernel) are vigorous with large, deep blue flowers and are used as annual bedding plants and for hanging baskets. 'Gentian Blue' is a seedpropagated blue cultivar sold by Thompson \& Morgan (Jackson, N.J.). Presently, this and several other commercial seed companies carry only unnamed cultivars of blue pimpernel. Several vegetatively propagated cultivars are offered in the trade including blue-flowered 'Skylover Blue' and 'Wildcat Blue' and orange-flowered 'Sunrise' and 'Wildcat Orange'. 'Wildcat Blue' and 'Wildcat Orange' (plant

Received for publication 29 Aug. 2003. Accepted for publication 23 Dec. 2003. Scientific contribution 2198 from the New Hampshire Agricultural Experiment Station. We thank Thomas M. Davis for valuable discussions; Amy Douglas and Deborah Schneider for assistance in greenhouse research; and Kenneth Schroeder, Dennis Werner, and John Hammond for critically reviewing the manuscript.

${ }^{1}$ To whom reprint requests should be addressed; e-mailrf@unh.edu. patents 10/721,990 and 10/721,991, respectively) were released from the ornamental breeding program at the University of New hampshire (UNH) in 2002.

Harborne (1968) found the flavonols quercetin and kaempferol in flowers of $A$. arvensis and $A$. linifolia, and cited research finding 3- and 3,5-glycosides of malvidin, delphinidin and pelargonidin in different color forms in $A$. arvensis. Ishikura (1981) identified malvidin 3-rhamnoside, luteolin, luteolin 7-glucoside and quercetin 3-rhamnoside in blue-flowered $A$. arvensis. Elsherif(2000) isolated chalcone synthase and flavanone 3-hydroxylase from flowers of A. monelli 'Skylover Blue' and 'Sunrise', and reported finding only pelargonidin derivatives in flowers of 'Sunrise' and only malvidin derivatives in flowers of 'Skylover Blue'.

We obtained A. monelli plants with a novel red flower color from hybridization between blue-and orange-flowered plants. The objectives of this study were to determine the biochemical basis of blue, orange and red flower colors and propose a genetic model for inheritance of flower color in A. monelli hybrids.

\section{Materials and Methods}

Plant material. Plants of A. monelli 'Sunrise' and seeds of 'Gentian Blue' were obtained from commercial sources and grown at UNH. All plants were maintained in $25-\mathrm{cm}$ baskets using 560 Scotts coir soiless medium (The Scotts Co., Marysville, Ohio) during cooler months or 360 Scotts coir medium in the summer, in a greenhouse with $21^{\circ} \mathrm{C}$ day $/ 18^{\circ} \mathrm{C}$ night set points. Fertilization was constant with a $20 \mathrm{~N}-4.3 \mathrm{P}-16.7 \mathrm{~K}$ fertilizer at a maximum of $150 \mathrm{mg} \cdot \mathrm{L}^{-1} \mathrm{~N}$. To ensure healthy growth, the growing medium $\mathrm{pH}$ was maintained between 5.7 to 6.3 and electroconductivity between 1.0 and $2.0 \mathrm{mS} \cdot \mathrm{cm}^{-1}$.
Hybridization. In winter and spring months, photoperiod was increased to $16 \mathrm{~h}$ using night-interruption lighting (with high pressure sodium lamps) from 2200 to $0200 \mathrm{hr}$ to induce flowering. Hybridizations were performed on emasculated, unopened buds and pedicels were tagged for identification. Approximately three weeks were allowed for fruit formation, and then watering was stopped to dry the plants and fruit. Fruit were harvested when brown and brittle on the outside, the placenta dry, and seeds a dark brown or black color. $\mathrm{F}_{1}$ and $\mathrm{F}_{2}$ seeds were sown in seed trays containing 360 Scotts coir, covered lightly with media and placed on a bench with intermittent mist. Trays were removed from the mist upon emergence of the first seedlings. Initially they were transplanted into small cell packs and later into 15- or 25-cm pots.

Color and $\mathrm{pH}$ determination. Flower

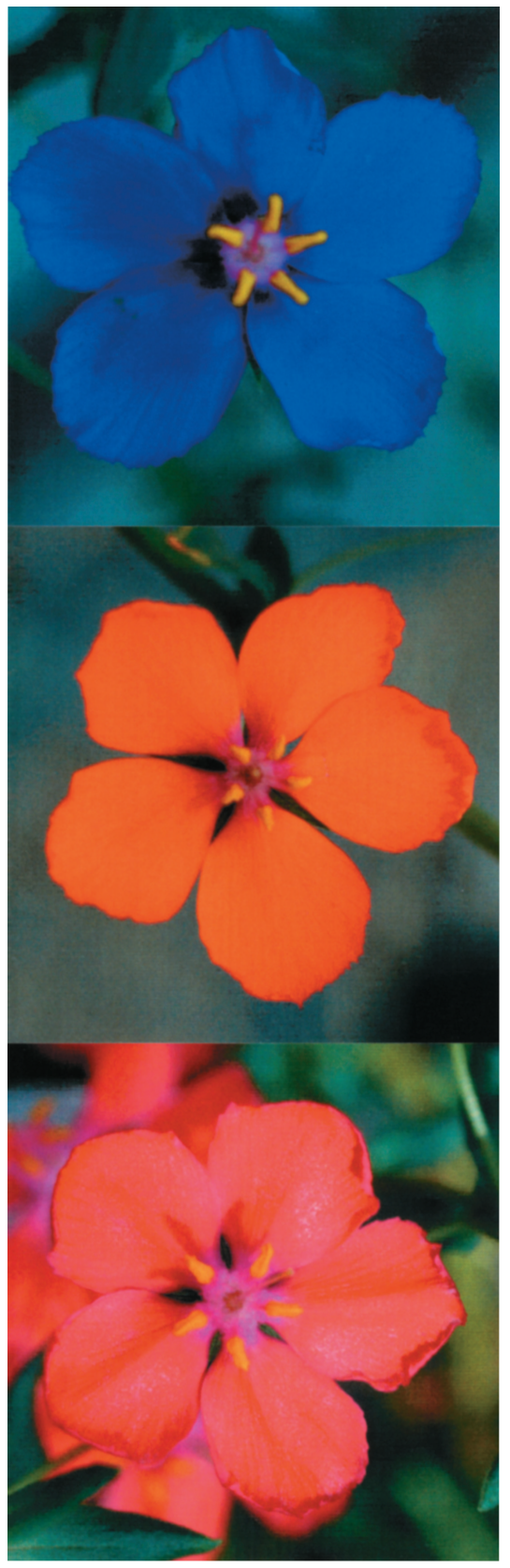

Fig. 1. Flowers of blue-, orange-, and red-flowered Anagallis monelli. 
color was determined using Munsell notation (Nickerson, 1946). The Munsell Book of Color (Munsell Color Services, New Windsor, N.J.) was used instead of the Royal Horticultural Society's Colour Charts because it is not possible to interpolate between color chips using the RHS Colour Charts. The $\mathrm{pH}$ of petal tissue was determined one day after flower opening. It was previously determined that the $\mathrm{pH}$ of an epidermal peel suspension accurately reflected the pH of a single cell (Griesbach, 1998; Stewart et al., 1975). Therefore, the upper epidermis was stripped and the epidermal strips from a single flower were combined. Strips were then ground into a suspension with distilled water and the $\mathrm{pH}$ of the suspension measured with a micro-pH meter (Sentron 501; Sentron, Inc., Federal Way, Washington D.C.). The $\mathrm{pH}$ measurements were recorded as a mean of 10 replications, each replicate representing the pooled tissue collected from a single flower.

Anthocyanidin analysis. Fresh flowers were ground in $1 \%(\mathrm{v} / \mathrm{v}) \mathrm{HCl}$ in methanol. The extract was filtered and reduced to dryness under reduced pressure at $40{ }^{\circ} \mathrm{C}$. The residue was dissolved in $1 \%(\mathrm{v} / \mathrm{v}) \mathrm{HCl}$ in methanol and clarified by centrifugation at $100,000 \mathrm{~g}_{\mathrm{n}}$ for $2 \mathrm{~min}$.

The anthocyanins were characterized by HPLC as previously described (Griesbach et al., 1991) using a $7.8 \times 300-\mathrm{mm}$ column of $5-\mu \mathrm{m}$ Bondapak $\mathrm{C} 18$ with a 30 -min linear gradient of $0 \%$ to $10 \%(\mathrm{v} / \mathrm{v})$ acetonitrile in aqueous $1.5 \%(\mathrm{v} / \mathrm{v})$ phosphoric acid and $15 \%$ (v/v) acetic acid, followed by a 10-min linear increase to $20 \%(\mathrm{v} / \mathrm{v})$ acetonitrile and finally held at 20\% (v/v) acetonitrile for an additional $10 \mathrm{~min}$. Flow rate was $1.0 \mathrm{~mL} \cdot \mathrm{min}^{-1}$ and detection was by absorption at $540 \mathrm{~nm}$.

Individual anthocyanin peaks were collected and acid hydrolyzed at $100{ }^{\circ} \mathrm{C}$ in $3 \mathrm{n}$ $\mathrm{HCl}$ for $1 \mathrm{~h}$. The hydrolyzed anthocyanidin products were characterized by HPLC as previously described (Griesbach et al., 1991) using a $7.8 \times 300-\mathrm{mm}$ column of 5- $\mu \mathrm{m}$ Bondapak C18 with a 20-min linear gradient of $0 \%$ to $15 \%(\mathrm{v} / \mathrm{v})$ acetonitrile in aqueous $1.5 \%(\mathrm{v} / \mathrm{v})$ phosphoric acid and $15 \%(\mathrm{v} / \mathrm{v})$ acetic acid and held at $15 \%(\mathrm{v} / \mathrm{v})$ for an additional $20 \mathrm{~min}$. Flow rate was $1.0 \mathrm{~mL} \cdot \mathrm{min}^{-1}$ and detection was by absorption at $540 \mathrm{~nm}$. Anthocyanidins were characterized by co-elution and comparative UV spectrophotometry with known standards (Harborne 1968).

\section{Results and Discussion}

Individual plants of 'Sunrise' and 'Gentian Blue' were self-incompatible and could not be selfed. 'Gentian Blue' is a commercial seed propagated line and breeds true for blue flower. When sister seedlings of 'Gentian Blue' were crossed, the resulting progeny $(n=86)$ were always true to color (data not shown). A polyploid ( $4 x$ ) form of 'Sunrise' was selfcompatible and the resulting progeny from self-pollinations were always true breeding for orange flowers (data not shown). Based on these observations, we considered A. monelli 'Sunrise' and 'Gentian Blue' to be homozygous for flower color.
'Sunrise' has low pollen and ovule fertility and is difficult to use in breeding. After many attempts, two $F_{1}$ seedlings of 'Gentian Blue' $x$ 'Sunrise' were obtained, both of which had orange flowers. Since the two $F_{1}$ seedlings were partially self-compatible, all $\mathrm{F}_{2}$ combinations ( $\mathrm{F}_{1}$-Orange 1 selfed, $\mathrm{F}_{1}$-Orange 2 selfed, $\mathrm{F}_{1}$-Orange $2 \times \mathrm{F}_{1}$-Orange 1 , and $\mathrm{F}_{1}$-Orange $1 \mathrm{x}$ $\mathrm{F}_{1}$-Orange 2) could be produced. None of these combinations resulted in large populations; therefore, all the populations were pooled. A total of $65 \mathrm{~F}_{2}$ plants were obtained, 28 of which were from $\mathrm{F}_{1}$-Orange 2 selfed, 19 from $\mathrm{F}_{1}$-Orange 1 selfed, and 18 from the $\mathrm{F}_{1}$-sib cross. In the $\mathrm{F}_{2}$ population, 55 plants had orange flowers, 8 plants had blue flowers, and 2 plants had red flowers (Fig. 1). This segregation ratio (55:8:2) fit a three gene model $(55: 9: 3)$ with a $\chi^{2}=$ $0.593, p=0.74$. Additional crosses were made ( $\mathrm{F}_{1}$-backcross, $\mathrm{F}_{3}$, etc.), but populations' sizes were too small for genetic analysis. However, these crosses resulted in additional red-flowered seedlings (Red3, Red4, Red5) that were used in further biochemical analysis.

A sample of five to seven plants for each color was used for biochemical analysis. Results of comparative UV spectrophotometry with known standards identified three different anthocyanidins: pelargonidin, delphinidin and malvidin(Table 1). Blue flower color (Munsell 5B 6.5/9.5) was due to predominance of malvi-

Table 1. Spectrophotometric profiles of HPLC anthocyanidin peaks in Anagallis monelli, and known standards.

\begin{tabular}{lcccc}
\hline Pigment & $\lambda_{\max }$ & $\mathrm{E}_{\mathrm{UV} \max } / \mathrm{E}_{\mathrm{V}_{\text {is.max }}}$ & $\mathrm{E}_{440} / \mathrm{E}_{\mathrm{Vis} \text { max }}$ & $\mathrm{Al}^{+}$shift \\
\hline Pelargonidin-3glucoside & 269,509 & 0.66 & 0.38 & No \\
Pelargonidin-3,5diglucoside & 268,505 & 0.47 & 0.18 & No \\
Cyanidin-3glucoside & 281,527 & 0.65 & 0.23 & Yes \\
Cyanidin-3,5diglucoside & 278,524 & 0.39 & 0.13 & Yes \\
Peonidin-3glucoside & 274,523 & 0.60 & 0.24 & No \\
Peonidin-3,5diglucoside & 277,522 & 0.45 & 0.13 & No \\
Delphinidin-3glucoside & 276,538 & 0.52 & 0.19 & Yes \\
Delphinidin-3,5diglucoside & 275,534 & 0.39 & 0.10 & Yes \\
Petunidin-3glucoside & 276,534 & 0.54 & 0.18 & Yes \\
Petunidin-3,5diglucoside & 273,535 & 0.44 & 0.12 & Yes \\
Malvidin-3glucoside & 276,534 & 0.54 & 0.18 & No \\
Malvidin-3,5diglucoside & 275,534 & 0.38 & 0.11 & No \\
Peak 1 (pelargonidin-3glycoside) & 268,509 & 0.70 & 0.39 & No \\
Peak 2(delphinidin-3glycoside) & 275,540 & 0.86 & 0.21 & Yes \\
Peak 3 (malvidin-3glycoside) & 276,540 & 0.69 & 0.21 & No
\end{tabular}

Table 2. Anthocyanidin composition of parents, $\mathrm{F}_{1}$ and $\mathrm{F}_{2}$ Anagallis monelli seedlings.

\begin{tabular}{|c|c|c|c|c|}
\hline \multirow[b]{2}{*}{ Plant } & \multirow[b]{2}{*}{ Color $^{y}$} & \multicolumn{3}{|c|}{ Anthocyanidin ${ }^{\mathrm{z}}$} \\
\hline & & Pelargonidin & Delphinidin & Malvidin \\
\hline 'Gentian Blue' & 5B $6.5 / 9.5$ & --- & 2 & 98 \\
\hline $\mathrm{F}_{2}$-Blue 1 & 5B $6.5 / 9.5$ & --- & 3 & 97 \\
\hline $\mathrm{F}_{2}$-Blue2 & 5B $6.5 / 9.5$ & --- & 13 & 87 \\
\hline $\mathrm{F}_{2}$-Blue 3 & 5B $6.5 / 9.5$ & --- & 14 & 86 \\
\hline $\mathrm{F}_{2}$-Blue 4 & 5B $6.5 / 9.5$ & 4 & 5 & 91 \\
\hline 'Sunrise' & 1.3YR 5.6/16 & 68 & 32 & --- \\
\hline $\mathrm{F}_{1}$-Orange1 & 1.3YR 5.6/16 & 71 & 5 & 24 \\
\hline $\mathrm{F}_{1}$-Orange 2 & 1.3YR 5.6/16 & 68 & 7 & 25 \\
\hline $\mathrm{F}_{2}$-Orange 1 & 1.3YR 5.6/16 & 52 & 6 & 42 \\
\hline $\mathrm{F}_{2}^{2}$-Orange2 & 1.3YR 5.6/16 & 70 & 12 & 18 \\
\hline $\mathrm{F}_{2}$-Orange 3 & 1.3YR 5.6/16 & 74 & 15 & 11 \\
\hline $\mathrm{F}_{2}$-Orange4 & 1.3YR 5.6/16 & 44 & 6 & 50 \\
\hline $\mathrm{F}_{2}-\operatorname{Red} 1$ & $0.3 \mathrm{R} 4.8 / 17$ & --- & 95 & 5 \\
\hline $\mathrm{F}_{2}-\operatorname{Red} 2$ & $0.3 \mathrm{R} 4.8 / 17$ & --- & 83 & 17 \\
\hline $\mathrm{F}_{2}-\operatorname{Red} 3$ & $0.3 \mathrm{R} 4.8 / 17$ & --- & 88 & 12 \\
\hline $\mathrm{F}_{2}-\operatorname{Red} 4$ & $0.3 \mathrm{R} 4.8 / 17$ & --- & 100 & --- \\
\hline $\mathrm{F}_{2}-\operatorname{Red} 5$ & $0.3 \mathrm{R} 4.8 / 17$ & --- & 94 & 6 \\
\hline
\end{tabular}

${ }^{\mathrm{z}}$ Mean percentage of total anthocyanidin.

${ }^{y}$ Munsell notation (Nickerson, 1946). din, while orange (Munsell 1.3YR 5.6/16) and red (Munsell 0.3R 4.8/17) colors were due to predominance of pelargonidin and delphinidin, respectively (Table 2 ). As expected, multiple cyanins were found in the different flower color types, since nearly all of the anthocyanin biosynthetic enzymes that have been studied will accept the different dihydroflavonol precursors as substrates (Fig. 2; Huitts et al., 1994). Different anthocyanin profiles in flowers are the result of differences in relative $\mathrm{K}_{\mathrm{m}}$ 's for the various substrates. When doing inheritance studies, the predominant anthocyanin is used as the phenotype (Griesbach et al., 1991).

It is generally assumed that delphinidin is the pigment responsible for blue flower colors and cyanidin is the pigment responsible for red flower colors (Forkmann, 1991). However, For example, the blue color in Meconopsis grandis Prain. is due to cyanidin (Takeda et al., 1996), while the red color in Petunia exserta tehmann is due to delphinidin (Ando et al., 2000). Under acidic conditions it is possible for delphinidin to appear red (Asen, 1976). The vacuole $\mathrm{pH}$ can affect the petal color by modifying the physical interaction between the electrons in the pigments (Brouillard, 1998). It has been shown in Petunia hybrida, for example, that a lower $\mathrm{pH}$ has a reddening effect on petal color, while higher $\mathrm{pH}$ has a there are exceptions to this generalization. 

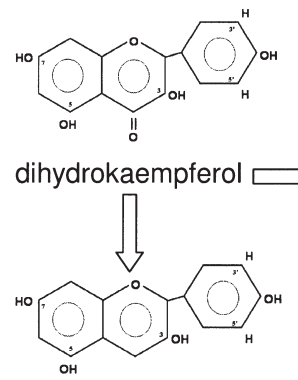

pelargonidin
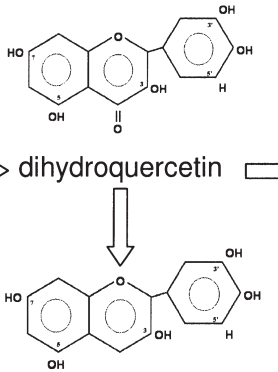

cyanidin

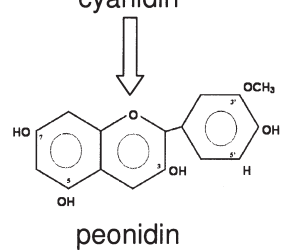

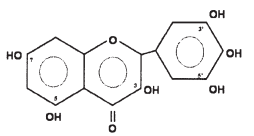

dihydromyricetin

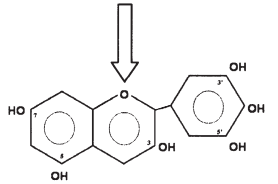

delphinidin<smiles>C=CCOc1c(-c2ccccc2OCC)ccc2ccccc12</smiles><smiles>Oc1ccc(-c2ccc3ccccc3c2)cc1</smiles>

malvidin
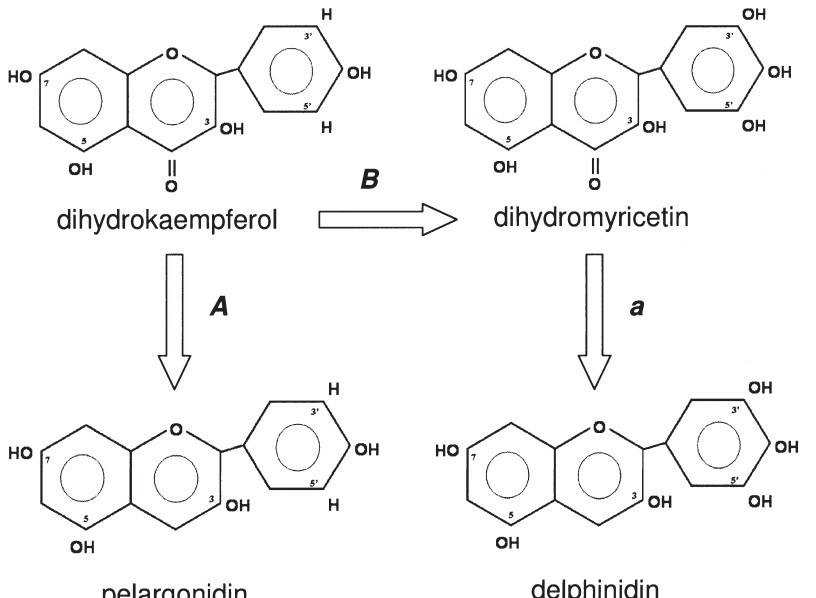

pelargonidin

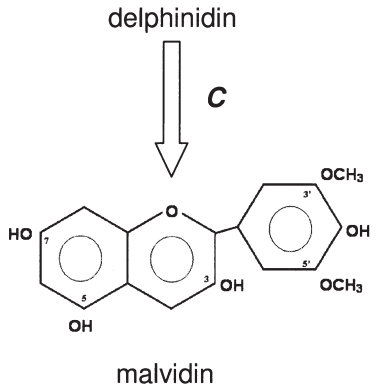

Fig. 2. Anthocyanin biosynthetic pathways. (a) The complete pathway as found in most plants. (b) The postulated pathway in Anagallis monelli with three genes $(A, B$, and C) controlling anthocyanidin production.

blueing effect (Griesbach, 1996). To determine whether petal $\mathrm{pH}$ was responsible for the red flower color, we compared petal $\mathrm{pH}$ of the blue- and red-flowered $\mathrm{F}_{2}$ plants that were used for biochemical analysis. Due to the small sample size, we also compared petal $\mathrm{pH}$ of additional blue $\mathrm{F}_{2}$ plants and red plants from advanced generations, totaling 10 plants for each flower color. There was no statistically significant difference in epidermal cell $\mathrm{pH}$ between the blue- and red-flowered plants (data not shown). The $\mathrm{pH}$ averaged 4.9 with a standard deviation of 0.2 .

Petunia exserta is another species that contains delphinidin and has red flowers that are not the result of a change in $\mathrm{pH}$ (Ando et al., 2000). In vitro, delphinidin appears red only at pHs below 3.0 (Asen, 1976). Other unknown factor(s) must be responsible for the red flower color of P. exserta and A. monelli. Further studies are needed to determine why flowers that contain delphinidin can appear red at $\mathrm{pH}$ values above 3.0.

The $\mathrm{F}_{2}$ segregation data (55 orange: 8 blue: 2 red) suggest that three genes are responsible for flower color in A. monelli. The general anthocyanin biosynthetic pathway (Fig. 2a) could be modified to explain the inheritance data (Fig. $2 b)$. In this modification, there are two alleles at the $A$ locus, ( $=A$ and $a$ ) with complete dominance of $A$ over $a$. The $A$ allele has a higher $\mathrm{K}_{\mathrm{m}}$ for dihydrokaempferol than dihydromyricetin, while the $a$ allele has the opposite substrate specificity. Therefore, the genotypes $A$ - -- -- and $-b b-$ will have orange flowers (pelargonidin), $a a B-C$ - will have blue flowers (malvidin), and $a a B-c c$ will have red flowers (delphinidin) with an expected $\mathrm{F}_{2}$ ratio $=52$ orange: 9 blue: 3 red. Our segregation ratio (55:8:2) does not deviate significantly from the expected ratio (52:9:3) with $\chi^{2}=0.593, p=0.74$.
This model has two assumptions: first, that dihydrokaempferol can be directly converted into dihydromyricetin without having to go through the dihydroquercetin intermediate as found in most plants; and secondly that delphinidin can be directly converted into malvidin without having to go through the petunidin intermediate (Fig. 2a). These assumptions are not unreasonable, for in Petunia there are known enzymes that can bypass these intermediates. In Petunia, there are two different cytochrome P450-dependent monooxygenases genes ( $\mathrm{Ht}$ and $H f$ ) that are responsible for creating the dihydroflavonols (Stotz et al., 1985; Shimada et al., 2001). Ht hydroxylates the 3 ' position, converting dihydrokaempferol into dihydroquecetin. Meanwhile, $H f$ can either convert dihydroquecetin into dihydromyricetin, or can bypass the intermediate converting dihydrokaempferol directly into dihydromyricetin. There are also two different anthocyanin-Omethyltransferase genes ( $M t$ and $M f$ ) that are responsible for converting delphinidin into petunidin and malvidin (Jonsson et al., 1983; Jonsson et al., 1984). If only $M t$ is expressed, then the 3'-methylated anthocyanin (petunidin) accumulates as the major product. If only $M f$ is expressed, then the 3',5'-methylated anthocyanin (malvidin) accumulates as the major product. Enzymes with similar specificities may be present in A. monelli.

The first red-flowered Anagallis plants obtained at UNH had very small flowers with petals that curled inwards, which was not an attractive trait. By selective breeding, we have now obtained plants with large and attractive red flowers and are trialing selections for release. Red-flowered plants are being used to develop cultivars with unique or novel colors. For example, an unusual violet-flowered seedling was discovered, which appears to be the result of a difference in anthocyanin pigmentation between the upper and lower epidermis. The inheritance of this new mutation is now being studied. Additionally, a new combination of anthocyanins (pelargonidin and malvidin) was discovered in a blue-flowered seedling (see $\mathrm{F}_{2}$-Blue4 in Table 1). Even though the concentration of pelargonidin was low, it may be possible to increase its concentration and create additional new colors through selective breeding.

\section{Literature Cited}

Ando, T., F. Tatsuzawa, N. Saito, M. Takahashi, Y. Tsunashima, H. Numajiri, H. Watanbe, H. Kokubun, R. Hara, H. Seki, and G. Hashimoto. 2000. Differences in the floral anthocyanin content of red petunias and $P$. exserta. Phytochemistry 54:495-501.

Asen, S. 1976. Known factors responsible for the infinite flower color variation. Acta Hort. 63:217-3223.

Brouillard, R. 1988. Flavonoids and flower color, p. 525-538. In: J.B. Harborne (ed.). The Flavonoids: Advances in research. Chapman \& Hall, London.

Clapham, A.R., T.G. Tutin, and D.M. Moore. 1987. Flora of the British Isles. $3^{\text {rd }}$ ed. Cambridge Univ. Press, New York.

Elsherif, T. 2000. Genetik und enzymologie der bildung außergerwöhlicher anthocyanidin-muster in blüten höherer pflanzen. $\mathrm{PhD}$ diss. Munich Technical Univ., Munich, Germany.

Forkmann, G. 1991. Flavonoids as flower pigments: the formation of the natural spectrum and its extension by genetic engineering. Plant Breed. 106:1-26.

Gibbs, P.E. and S. Talavera. 2001. Breeding system studies with three species of Anagallis (Primulaceae): Self-incompatibility and reduced female fertility in A. monelli L. Ann. Bot. 88:139-144.

Griesbach, R.J., S. Asen, and B.A. Leonhardt. 1991. Petunia hybrida anthocyanins acylated with caf- 
feic acid. Phytochemistry 30:1729-1731.

Griesbach, R.J. 1996. The inheritance of flower color in Petunia hybrida Vilm. J. Hered. 87:241-245.

Griesbach, R.J. 1998. The effect of the Ph6 gene on the color of Petunia hybrida flowers. J. Amer. Soc. Hort. Sci. 123:647-650.

Harborne, J.B. 1968. Comparative biochemistry of the flavonoids. VII. Correlations between flavonoid pigmentation and systematics in the family Primulaceae. Phytochemistry 7:1215-1230.

Huitts, H.S., A.G. Gerats, M.M. Kreike, J.N. Mol, and R. Koes. 1994. Genetic control of dihydroflavonol 4-reductase gene expression in Petunia hybrida. Plant J. 6:295-310.

Ishikura, N. 1981. Flavonoids in the petal cells of Anagallis arvensis f. coerulea containing a blue crystalline anthocyanin. Z. Pflanszenphysiol. Bd. 103:469-473.

Jonsson, L.M.V., P. deVlaming, H. Wiering, M.E.G. Aarsman, and A.W. Schram. 1983. Genetic control of anthocyanin-0-methyl-transferase activity in flowers of Petunia hybrida. Theor. Appl. Genet. 66:349-355.

Jonsson, L.M.V., M.E.G. Aarsman, J.E. Poulton, and A.W. Schram. 1984b. Properties and genetic control of four methyltransferases involved in methylation of anthocyanins in flowers of Petunia hybrida. Planta 160:174-179.

Källersjö, M., G. Bergqvist, and A.A. Anderberg. 2000. Generic realignment in primuloid families of the Ericales: 1. A phylogenetic analysis based on DNA sequences from three chloroplast genes and morphology. Amer. J. Bot. 87:1325-1341.

Nikerson, D. 1946. The Munsell color system. Illum. Eng. 61:549-560.

Shimada, Y., M. Ohbayashi, R. Nakano-Shimada, Y. Okinaka, S. Kiyokawa, and Y. Kikuchi. 2001. Genetic engineering of the anthocyanin biosynthetic pathway with flavonoid-3',5'-hydroxylase: Specific switching of the pathway in petunia. Plant Cell Rpt. 20:456-462.

Stewart, R.N., K.H. Norris, and S. Asen. 1975. Microspectrophotometric measurement of $\mathrm{pH}$ and $\mathrm{pH}$ effects on the color of petal epidermal cells. Phytochemistry 14:937-942.

Stotz, G., P. deVlaming, H. Wiering, A.W. Schram, and G. Forkman. 1985. Genetic and biochemical studies on flavonoid 3'-hydroxylation in flowers of Petunia hybrida. Theor. Appl. Genet. 70:300-305.

Takeda, K., S. Yamaguchi, K. Iwata, Y. Tsujino, T. Fujumor, and S. Huisain. 1996. A malonylated anthocyanin and flavonols in the blue flowers of Meconopsis. Phytochemistry 42:863-865.

Talavera, S., L. García-Pérez, M. Arista, and P.L. Ortiz. 1997. Números cromosomáticos de plantas occidentales. Anal. Jard. Bot. Madrid. 55:136.

Talavera, S., P.E. Gibbs, M.P. Fernández-Piedra, and M.A. Ortiz-Herrera. 2001. Genetic control of self-incompatibility in Anagallis monelli (Primulaceae:Myrsinaceae). Heredity 87:589-597.

Tutin, T.G., V.H. Heywood, N.A. Burges, D.M. Moore, D.H. Valentine, S.M. Walters, and D.A. Webbs (eds.). 1972. Flora Europaea. vol. 3. Cambridge Univ. Press. 